\title{
Aortoenteric fistula at the site of esophagojejunostomy after laparoscopic total gastrectomy: report of a case.
}

\section{AUTHOR(S):}

Gunji, Shutaro; Okabe, Hiroshi; Obama, Kazutaka; Sakai, Yoshiharu

\section{CITATION:}

Gunji, Shutaro ...[et al]. Aortoenteric fistula at the site of esophagojejunostomy after laparoscopic total gastrectomy: report of a case.. Surgery today 2014, 44(11): 2162-2166

\section{ISSUE DATE:}

\section{4-01-28}

URL:

http://hdl.handle.net/2433/198572

\section{RIGHT:}

The final publication is available at Springer via http://dx.doi.org/10.1007/s00595-0140834-3.; この論文は出版社版でありません。引用の際には出版社版をご確認ご利用くだ さい。; This is not the published version. Please cite only the published version. 
1

2

3

4

5

6

7

8

9

10

11

12

13

14

15

16

17

18

19

20

21

22

23

24

25

26

27

28

29

30

31

32

33

34

Aortoenteric fistula at the site of esophagojejunostomy after laparoscopic total gastrectomy: Report of a case

Shutaro Gunji, Hiroshi Okabe, Kazutaka Obama, Yoshiharu Sakai

Department of Surgery, Graduate School of Medicine, Kyoto University, 54 Kawahara-cho, Shogoin,

Sakyo-ku, Kyoto, Japan

hokabe@kuhp.kyoto-u.ac.jp

Tel: +81-75-751-4108

Fax: +81-75-751-4646 


\section{Abstract}

2 Fistulas between the aorta and the digestive tract are rare complications. There are some reports of

3 aortoesophageal fistulas that are rare but fatal complications after esophagectomies or esophageal stent

4 implantations. An aortoenteric fistula (AEF) occasionally occurs after an aortic intervention or

5 vascular procedures; however it is quite rare after gastrointestinal surgeries. This paper demonstrates a

6 case of an AEF after laparoscopic total gastrectomy for an advanced gastric cancer. This is the first

7 case report describing an AEF after the so-called overlap method of esophagojejunal anastomosis.

8 This report describes a case of 77-year-old Japanese woman who underwent laparoscopic total

9 gastrectomy and esophagojejunal anastomosis with Roux-en-Y reconstruction for advanced gastric

10 cancer. The patient exhibited bacterial peritonitis five days after the operation, due to a partial necrosis

11 and perforation of the small intestine. The patient was treated successfully with laparoscopic partial resection of the small intestine. However, the patient died of massive hematemesis caused by the AEF 30 days after the primary surgery.

Key word; Aortoenteric fistula, laparoscopic total gastrectomy, overlap anastomosis 


\section{Introduction}

Fistulas between the aorta and a digestive tract are quite rare complications after gastrointestinal surgeries. There are some reports of aortoesophageal fistulas after esophagectomy as fatal complications. Previous studies reported anastomotic leakage or peptic ulceration of the gastric tube as a cause of fistula formation [1-4]. However, an aortoenteric fistula (AEF) after total gastrectomy is a quite rare complication. Recent technical advancements in endoscopic surgery have increased the number of laparoscopic gastrostomies for gastric cancer. Several types of anastomotic techniques have been developed; experienced surgeons have even made advancements that allow completely laparoscopic total gastrectomies [5-7]. This paper describes a case of an AEF at the site of esophagojejunal anastomosis after laparoscopic total gastrectomy. This is the first case report describing an AEF after applying the so-called overlap method of esophagojejunal anastomosis [6, 7].

\section{Case presentation}

The patient was a 77-year-old Japanese female referred with a diagnosis of advanced gastric cancer. The patient had been receiving medication for type II diabetes and hypertension. Preoperative examinations included computed tomography, endoscopy, and an upper gastrointestinal series. Endoscopy showed that the tumor had invaded the esophagus about $15 \mathrm{~mm}$ above the esophagogastric junction. Computed tomography demonstrated lymph node metastasis around the cardia and the esophageal hiatus. The patient was diagnosed withT3N2M0 Stage IIIB, according to the TNM classification of Union for International Cancer Control (UICC) edition 6.

The patient received neoadjuvant chemotherapy using a combination of S-1 and cisplatin. S-1 (80 $\mathrm{mg} /$ day) was orally administered for three weeks, and cisplatin $\left(60 \mathrm{mg} / \mathrm{m}^{2}\right)$ was given intravenously on day 8. This regimen was repeated every five weeks for a total of two cycles. Two courses of chemotherapy did not significantly change the size of the primary lesion or the metastatic lymph nodes. There were no new lesions or progression, thus the disease was judged to be stable disease (SD) according to the response evaluation criteria in solid tumors (RECIST, version 1.1). Because her tumor was still diagnosed as resectable, total gastrectomy was planned. The patient participated in a clinical trial of a phase II study of laparoscopic gastrectomy for clinical stage II or higher gastric cancer (UMIN000002085), and successfully underwent a laparoscopic total gastrectomy with D2 lymph node dissection and a radical lymph node resection in the lower mediastinum; this included lymph nodes No. 20, 110 as per the UICC edition 6 classification. During the operation, SonoSurg TM (Olympus Medical, Tokyo, Japan) was used.

Following the removal of the specimen, laparoscopic Roux-en Y reconstruction was done. The lower esophagus was resected to obtain a safety margin, and esophagojejunostomy was created in the lower mediastinum using linear staplers, using the overlap method. A side-to-side anastomosis was created between the left dorsal side of the esophagus and the jejunal limb, and the entry hole was closed using an interrupted hand-sewn technique [5, 7].

The tumor was histopathologically diagnosed as a poorly differentiated adenocarcinoma of the stomach. Lymph node metastases were found in 10 among 28 removed nodes, and the pathological 
stage was pT3N2M0, Stage IIIB (Fig 1 A\&B). The proximal and distal margins were negative, thus $\mathrm{R} 0$ resection was achieved.

On postoperative day 4, the patient exhibited severe abdominal pain. A computed tomography (CT) scan was taken after administration of gastrographin, and it did not reveal any sign of anastomotic leakage. (Fig. 2A\&B) However, a significant amount of gram positive and negative cocci were detected from the drainage fluid, indicating a bacterial peritonitis. During the emergency operation, a segmental necrotic change of the ileum with small perforation was found, which was located at $45 \mathrm{~cm}$ on the oral side from the ileocecum, and we thought that this caused peritonitis. The affected ileum was resected, and the abdominal cavity was washed with large amounts of saline. Neither the abscess nor any evidence of leakage was observed in the upper abdomen, and ischemic ulcer associated with thromboembolic occlusion of a mesenteric artery was determined pathologically. Following the operation, the patient was treated with endotoxin absorption therapy, continuous hemodiafiltration, appropriate intravenous antibiotics, and total parenteral nutrition in the intensive care unit. The patient gradually recovered and restarted a soft diet 17 days after the emergency operation. We measured the concentration of amylase in the drainage fluid multiple times, although the level had been less than $107 \mathrm{IU} / \mathrm{L}$ during the clinical course.

However, the patient had a sudden hematemesis on postoperative day 30. An aortoenteric fistula (AEF) was suspected in addition to the massive amount of hematemesis. The patient was immediately transferred to an angiography room for a radiological intervention. However, the patient died from hemorrhagic shock before the procedure was initiated. The autopsy revealed AEF at the site of esophagojejunostomy (Fig 3). Neither a hemorrhage nor abscess was observed in the abdominal cavity. Rapid exsanguination from the fistula was determined to have been the cause of death.

\section{Discussion}

Fistulas between the aorta and a digestive tract are quite rare complications after gastrointestinal surgeries. AEFs occur after aortic interventions or vascular procedures, most commonly after an open abdominal aortic aneurysm repair because of mechanical erosion or infection of the suture line and the prosthetic graft into the overlying duodenum [8]. The other causes of AEFs are gallstones, periaortic malignancies or metastases, peptic ulcers, complicated diverticulitis, appendicitis, and radiation therapy [9-13]. There are some recent reports of large-scale randomized control studies of gastric surgery [10, 14-16]. Major complications after total gastrectomy include anastomotic leakage, pancreatic fistulas, abdominal abscesses, intestinal obstructions, and pneumonia [17-19]. However, there are no reports of AEF following either open or laparoscopic total gastrectomies [5-7].

This rare but devastating complication requires prompt surgical or interventional management. There are a few cases of successful treatment of aortoesophageal fistulas [20, 21]. Treatment generally requires closing of the aortic stump and repair of the fistula or endovascular intervention [20,22, 23]. As a result, the difficulty in predicting this complication remains a critical 
problem [8, 24].

The role of NAC in the treatment of gastric cancer has been under discussion. [25] NAC can increase the rate of achievement of R0 resection or pathological complete response (pCR). However, Yeong et al. reported that NAC increased the incidence of surgical complications, although there were no deaths directly related to surgical site failures. [26] Schuhmacher et al. also reported that the total number of postoperative complications was higher in the neoadjuvant cohort than the surgery-alone cohort. [27] However, there were no fatal complications documented during surgery. On the other hand, Ge et al. reported the rate of complications in the neoadjuvant cohort was not obviously higher than in the surgery-alone cohort. [28] According to these reports, it seems to be difficult to deny the possibility that NAC may have affected the incidence of AEF in our case. However, there are no reports that describe the incidence of AEF not only after NAC but also after surgeries in gastric cancer patients.

The current case was similar to esophageal fistulas between the aorta and the gastric tube. Le Roux reported 8 cases of fistulas between the gastric tube and aorta from 418 patients after esophagectomy [29]; the fistula was located at the anastomosis in 7 cases and it was at the closure line of the gastric tube in one case. He suggested that the two most common etiological factors of AEFs were anastomotic leakage, and the exposure of aortic sheath by extensive lymph node dissection. In the current case, a radical lymph node resection in the lower mediastinum was performed because of evident lymph node metastasis. This resulted in the exposure of the descending aorta. A review of CT after the first operation revealed that the staple line of the anastomosis was in direct contact with the descending aorta (Fig 2A\&B).

There may be some reasons for the fistula in our case, for example, anastomotic leakage, pancreatic fistula, infection, sustained contact between the staples and the aorta, chemotherapy, energized devices such as ultrasonically activated scalpels and so on. Among them, we thought the persistent contact of the staple line could have caused erosion of the aortic wall and lead to the formation of the aortoenteric fistula, because there was no sign of anastomotic leakage, pancreatic fistula or concomitant abscess formation during the clinical course or autopsy (Fig $3 \mathbf{8} \mathbf{4}$ ). Therefore, we would like to emphasize the importance of being mindful of the direction of the closure line of the anastomosis or adverse covering the staple line by adding sero-muscular sutures to avoid direct contact with other organs. This anastomotic technique is new, and we don't have enough experience to discuss the pros and cons of this technique. More data is necessary for further clinical practice.

In conclusion, though we couldn't obtain the clear reason for the cause of the fistula from the autopsy, we hypothesized that it could have been the result of persistent contact of and subsequent abrasion by the staple line upon the aortic sheath. We would like to declare the importance of immediate intervention or surgery if AEF is suspected. (1) 


\section{$1 \quad$ Figure legends}

2

3

4

5

6

\section{Figure 1}

(A) The resected stomach. The tumor occupied the lesser curvature of the gastric corpus. However, no tumor cell was detected at the proximal end $(*)$ and the distal end $(* *)$.

(B) The tumor was histopathologically diagnosed to be a poorly differentiated adenocarcinoma (por1) of the stomach. Lymph node metastasis was detected among ten of the twenty-eight resected lymph nodes. The pathological stage was pT3 (SE) N2 M0 Stage IIIB.

\section{Figure 2}

Contrast enhanced CT taken 4 days after the first operation demonstrated a small amount of fluid collection at the subphrenic lesion and atelectasis. Arrows indicate the site of the anastomosis and staples, which are close to the descending aorta. (A) Axial plane. (B) Coronal plane.

\section{Figure 3}

An autopsy revealed the fistula at the site of the anastomosis (A) and communicated to the descending aorta (B). Arrows indicate the site of fistula. The broken line indicates the anastomosis between the esophagus $(*)$ and the jejunum $(* *)$.

Figure 4

The fistula located at the top of a triangular anastomosis, where the staple line might have been exposed to the descending aorta.

Conflict of interest statement: Yoshiharu Sakai and other co-authors have no conflict of interest. 2 
1. Katyal D, Jewell LD, Yakimets WW: Aortoesophageal fistula secondary to benign barret ulcer - a rare cause of massive gastrointestinal hemorrhage. Canadian Journal of Surgery 1993, 36:480-482. 2. Kawaguchi Y, Fu K, Morimoto T, Shimizu T, Izumi Y, Miyazaki A: Aortoesophageal fistula after radiation therapy for esophageal cancer (with video). Gastrointestinal Endoscopy 2011, 74:922-923.

3. Levine MS, Fisher AR, Rubesin SE, Laufer I, Herlinger H, Rosato EF: Complications after total gastrectomy and esophagojejunostomy - radiologic evaluation. American Journal of Roentgenology 1991, 157:1189-1194.

4. Schweigert M, Dubecz A, Stadlhuber RJ, Muschweck H, Stein HJ: Risk of Stent-Related Aortic Erosion After Endoscopic Stent Insertion for Intrathoracic Anastomotic Leaks After Esophagectomy. Annals of Thoracic Surgery 2011, 92:513-519. 5. Inaba K, Satoh S, Ishida Y, Taniguchi K, Isogaki J, Uyama I: Overlap Method: Novel Intracorporeal Esophagojejunostomy after Laparoscopic Total Gastrectomy. Journal of the American College of Surgeons 2010, 211:E25-E29.

6. Okabe H, Obama K, Tanaka E, Nomura A, Kanaya S, Sakai Y: Intracorporeal esophagojejunal anastomosis after laparoscopic total gastrectomy for patients with gastric cancer. Surgical Endoscopy and Other Interventional Techniques 2009, 23:2167-2171. 7. Tsujimoto H, Uyama I, Yoshida K, Horiguchi H, Aosasa S, Ono S, et al: Outcome of overlap anastomosis using a linear stapler after laparoscopic total and proximal gastrectomy. Langenbecks Archives of Surgery 2012, 397:833-840.

8. Simon T, Feller E: Diverse Presentation of Secondary Aortoenteric Fistulae. Case reports in medicine 2011, 2011.

9. Aladgem D, Mazor A, Kashtan H, Ostrzega N, Barak Y, Wiznitzer T: Colonic bleeding due to rupture of an isolated iliac artery aneurysm into a cecal carcinoma. Postgraduate Medical Journal 1988, 64:636-637.

10. Singh S, Ladabaum U, Hovsepian DM, Triadafilopoulos G: Cancer-Associated Aorto-Enteric Fistula. Digestive Diseases and Sciences 2012, 57:625-629.

11. Galler AS, Mindadze N, Fulda G, Rao DB: Emergency repair of a radiation-induced aortoesophageal fistula with endograft: Report of a case. Surgery Today 2011, 41:266-270. 12. Villalba MR, Villalba MR: Development of a Gastric Pouch-Aorto-Colic Fistula as a Complication of a Revisionary Open Roux-en-Y Gastric Bypass. Obesity Surgery 2009, 19:265-268. 13. Bonenkamp JJ, Hermans J, Sasako M, van de Velde CJH, Dutch Gastric Canc G: Extended lymph-node dissection for gastric cancer. New England Journal of Medicine 1999, 340:908-914. 14. Bonenkamp JJ, Songun I, Hermans J, Vanelk P, Obertop H, Gouma DJ, Taat CW, et al: Randomized comparizon of morbidity after D1 and D2 dissection for gastric-cancer in 966 Dutch patients. Lancet 1995, 345:745-748. 
1 15. Cuschieri A, Weeden S, Sydes M, Fayers P, Surgical Cooperative G: Patient survival after

2 D-1 and D-2 resections for gastric cancer: long-term results of the MRC randomized surgical trial.

3 British Journal of Cancer 1999, 79:1522-1530.

4 16. Sano T, Sasako M, Yamamoto S, Arai K, Yamamura Y, Okajima K: Gastric cancer surgery:

5 Morbidity and mortality results from a prospective randomized controlled trial comparing D2 and

6 extended para-aortic lymphadenectomy - Japan Clinical Oncology Group Study 9501. Journal of 7 Clinical Oncology 2004, 22:2767-2773.

8 17. Budisin N, Budisin E, Golubovic A: Early complications following total gastrectomy for 9 gastric cancer. Journal of Surgical Oncology 2001, 77:35-41.

10 18. Sowa M, Kato Y, Nakanishi I, Kubo T, Chung YS: Complications of total gastrectomy for gastric-cancer - with special refference to anastomotic failure. Anticancer Research 1992, 12:1427-1430.

19. Topal B, Leys E, Ectors N, Aerts R, Penninckx F: Determinants of complications and adequacy of surgical resection in laparoscopic versus open total gastrectomy for adenocarcinoma. Surgical Endoscopy and Other Interventional Techniques 2008, 22:980-984.

20. Sato O, Miyata T, Matsubara T, Shigematsu H, Yasuhara H, Ishimaru S: Successful surgical treatment of aortogastric fistula after an esophagectomy and subsequent endovascular graft placement: Report of a case. Surgery Today-the Japanese Journal of Surgery 1999, 29:431-434.

21. Unosawa S, Hata M, Sezai A, Shimura K, Furukawa N, Minami K: Surgical treatment of an aortoesophageal fistula caused by stent implantation for esophageal stenosis: Report of a case. Surgery Today 2008, 38:62-64.

22. Danneels MIL, Verhagen HJM, Teijink JAW, Cuypers P, Nevelsteen A, Vermassen FEG: Endovascular repair for aorto-enteric fistula: A bridge too far or a bridge to surgery? European Journal of Vascular and Endovascular Surgery 2006, 32:27-33. 23. Song Y, Liu Q, Shen H, Jia X, Zhang H, Qiao L: Diagnosis and management of primary aortoenteric fistulas - experience learned from eighteen patients. Surgery 2008, 143:43-50. 24. Antinori CH, Andrew CT, Santaspirit JS, Cody WC, DiPaola DJ, Manuele VJ: The many faces of aortoenteric fistulas. American Surgeon 1996, 62:344-349. 25. Misra S, Pedroso FE, DiPasco PJ, Ardalan B, Koniaris LG: Does neoadjuvant chemotherapy improve outcomes for patients with gastric cancer? Journal of Surgical Research 2012, 178:623-631. 26. An JY, Kim KM, Kim YM, Cheong J-H, Hyung WJ, Noh SH: Surgical Complications in Gastric Cancer Patients Preoperatively Treated with Chemotherapy: Their Risk Factors and Clinical Relevance. Annals of Surgical Oncology 2012, 19:2452-2458.

27. Schuhmacher C, Gretschel S, Eisenberger CF, Haag C, Mauer ME, Hasan B, Welch J, et al: Neoadjuvant Chemotherapy Compared With Surgery Alone for Locally Advanced Cancer of the Stomach and Cardia: European Organisation for Research and Treatment of Cancer Randomized Trial 40954. Journal of Clinical Oncology 2010, 28:5210-5218. neoadjuvant chemotherapy in locally-advanced gastric/gastroesophageal cancer: A meta-analysis. 
$1 \quad$ World Journal of Gastroenterology 2012, 18:7384-7393.

2 29. Leroux BT: Aortic erosion complicating oesophago-gastrectomy. British Journal of Surgery 3 1961, 49.

4

5

6 
A

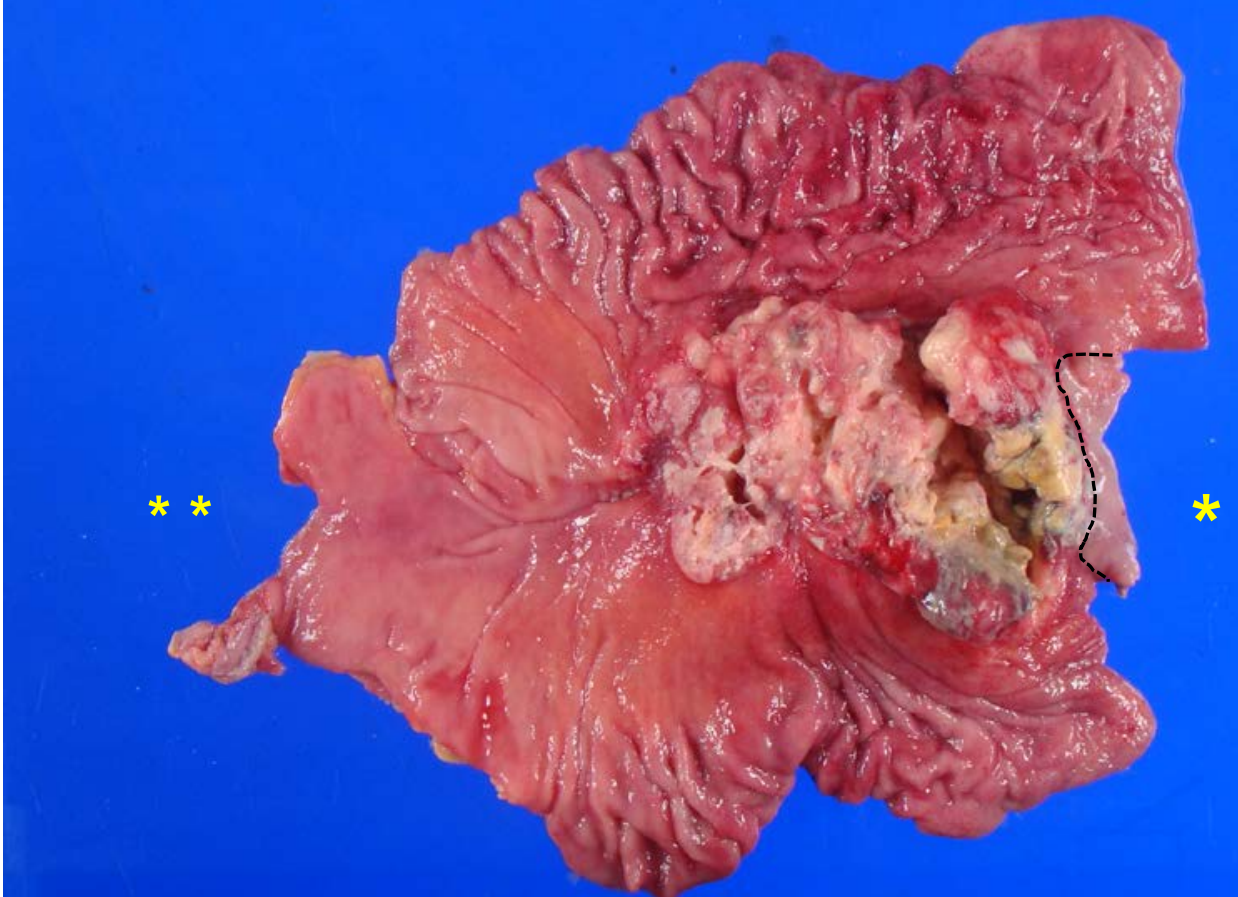

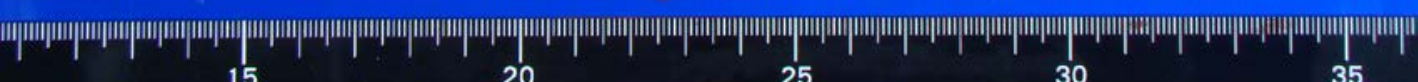

20

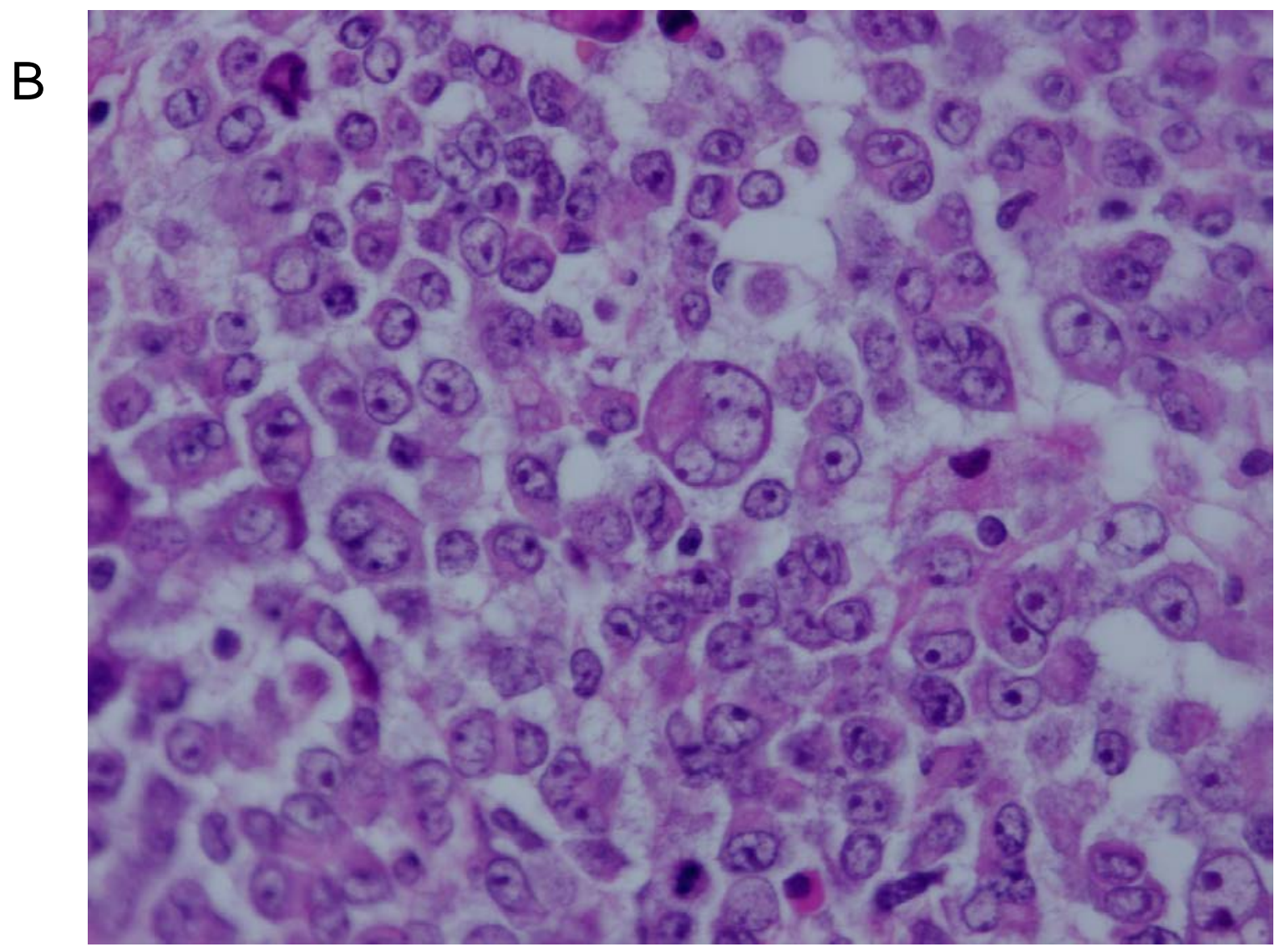

Fig.1 
A

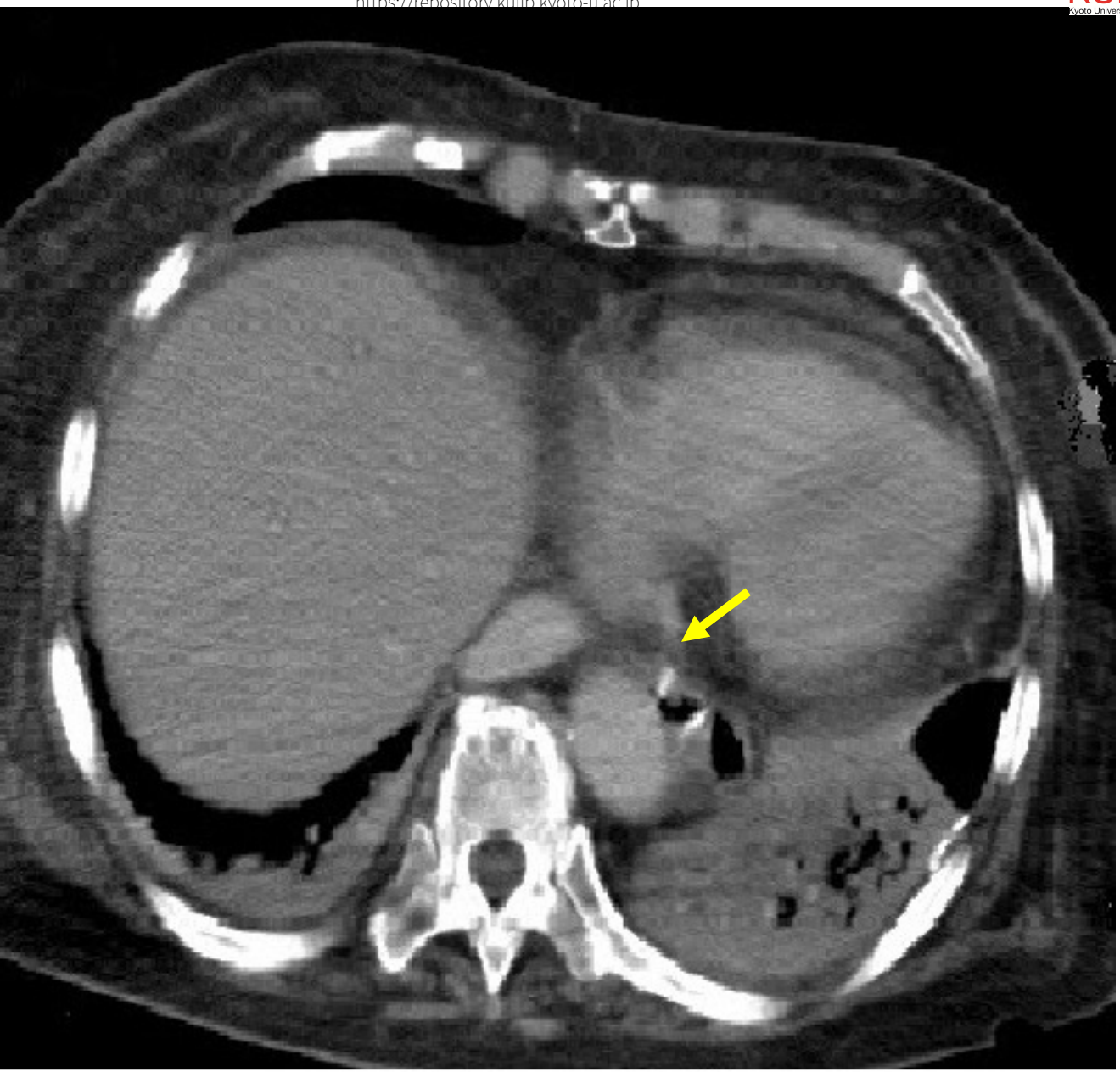

B

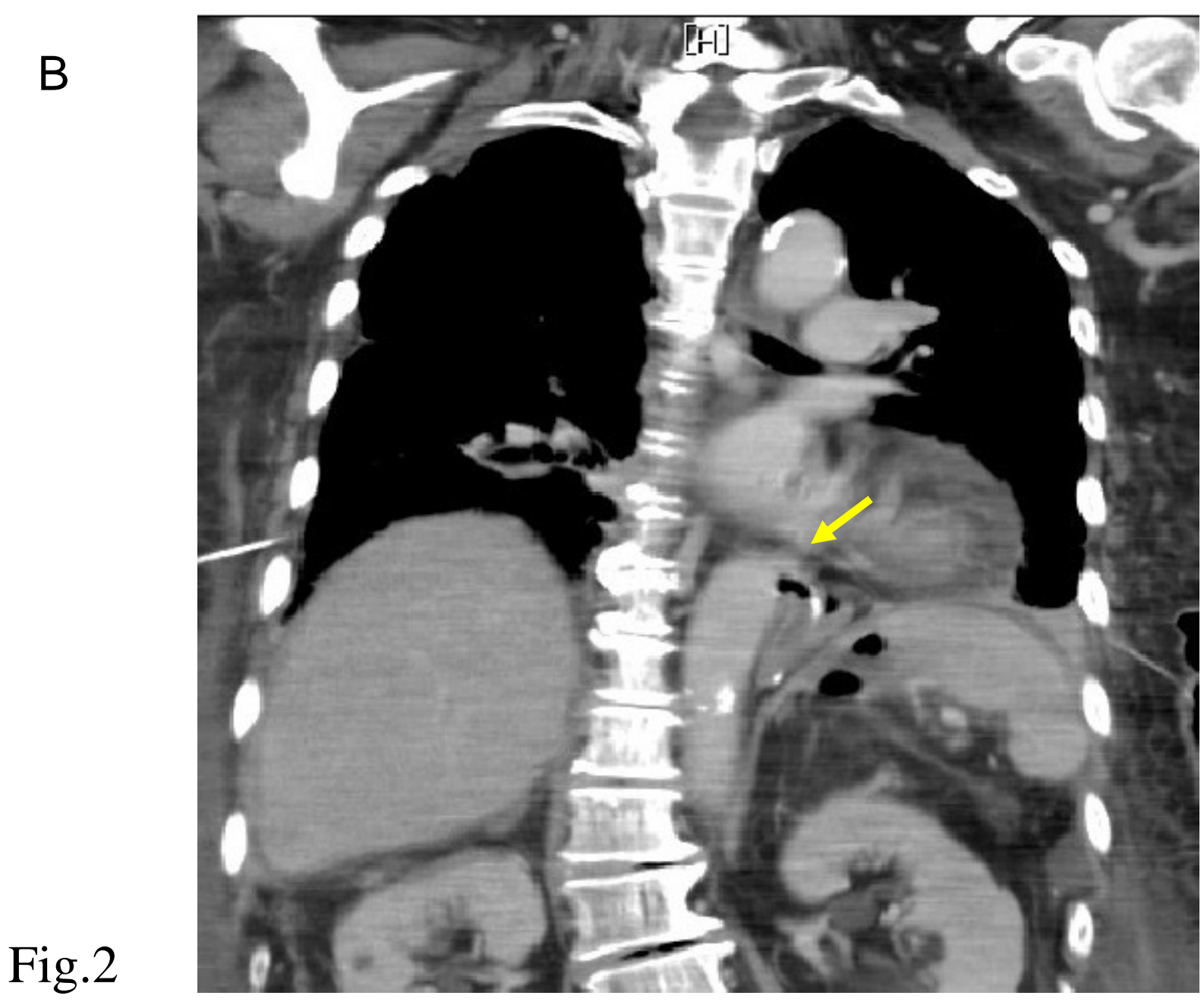

Fig. 2 


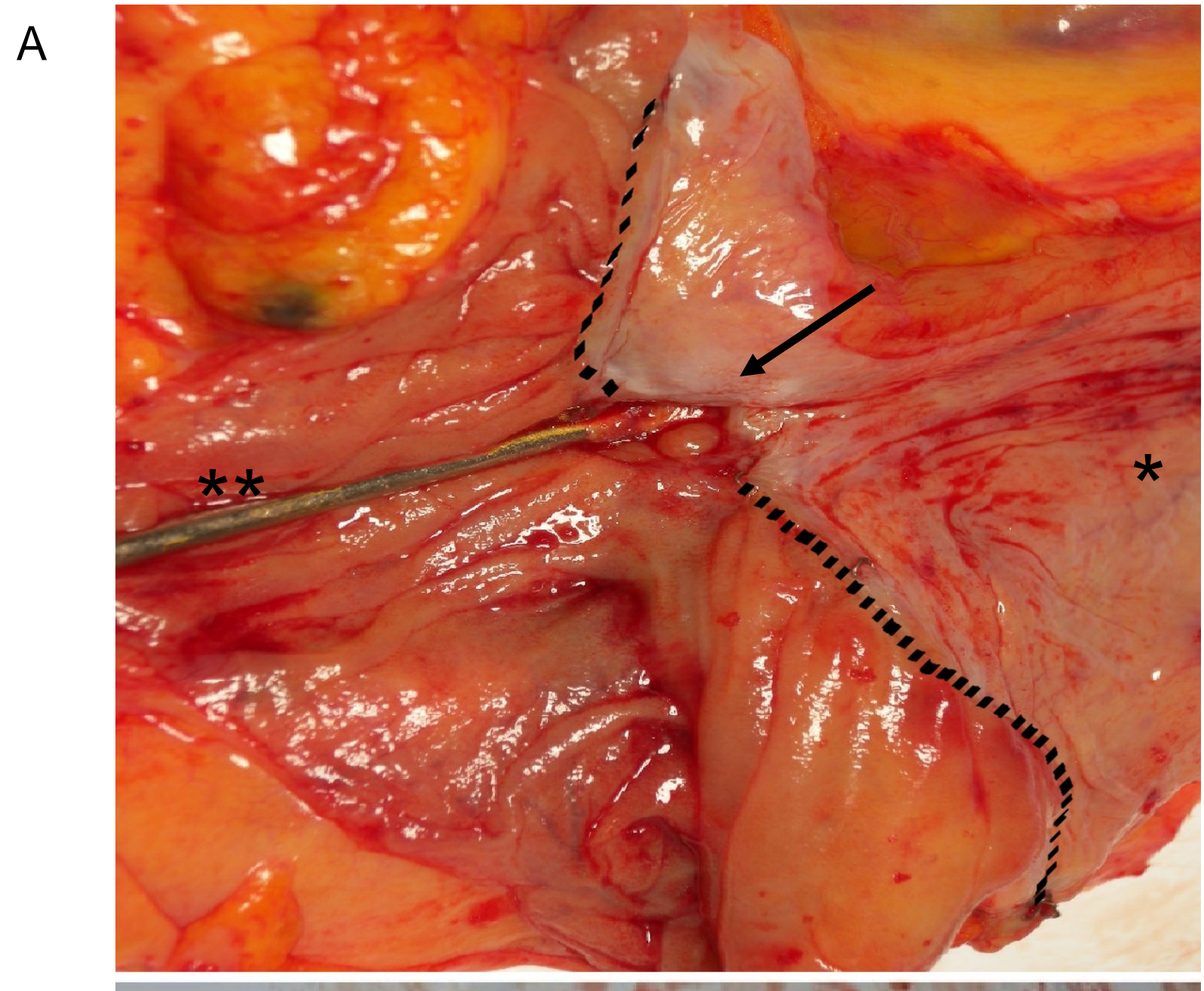

B

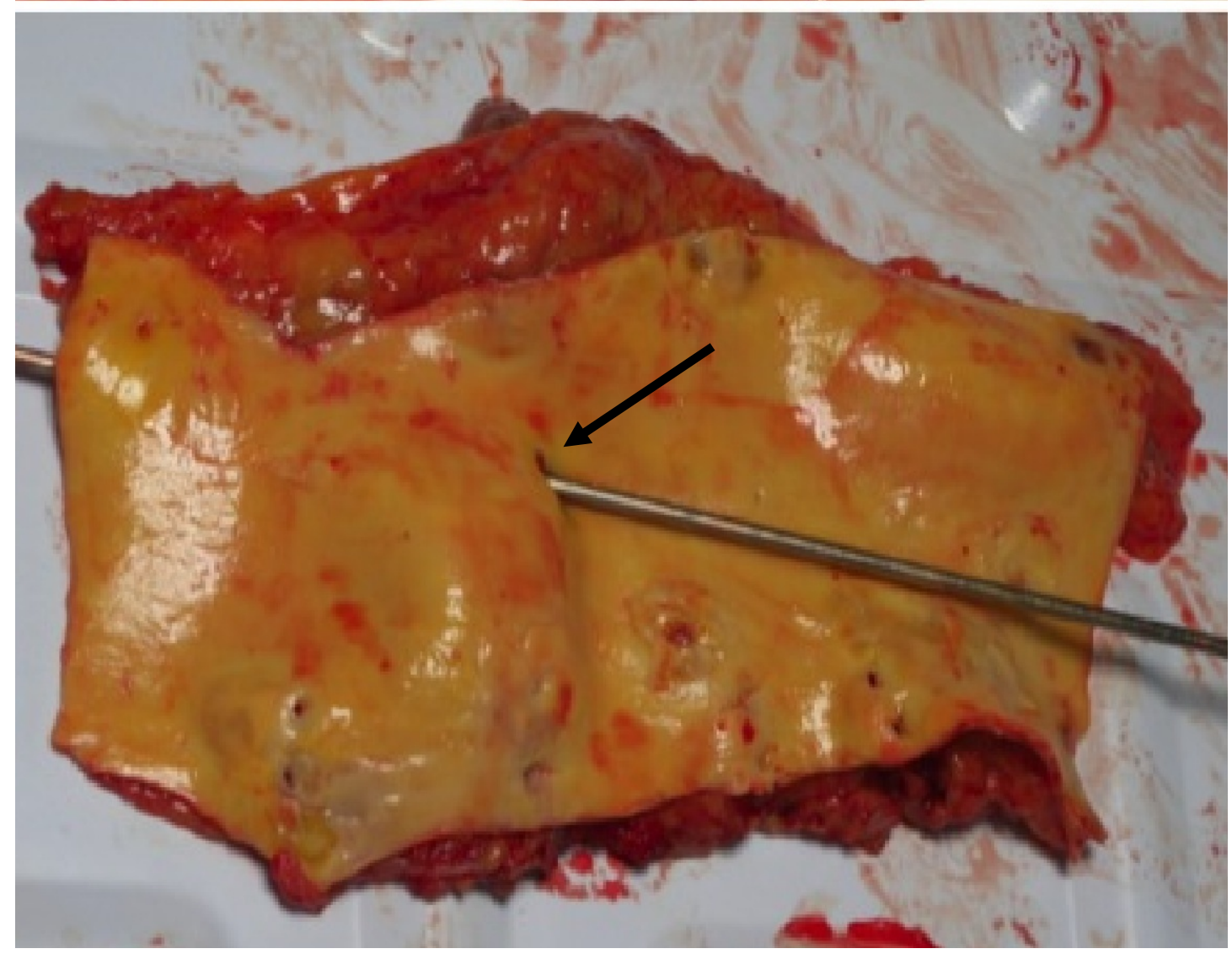

Fig.3 


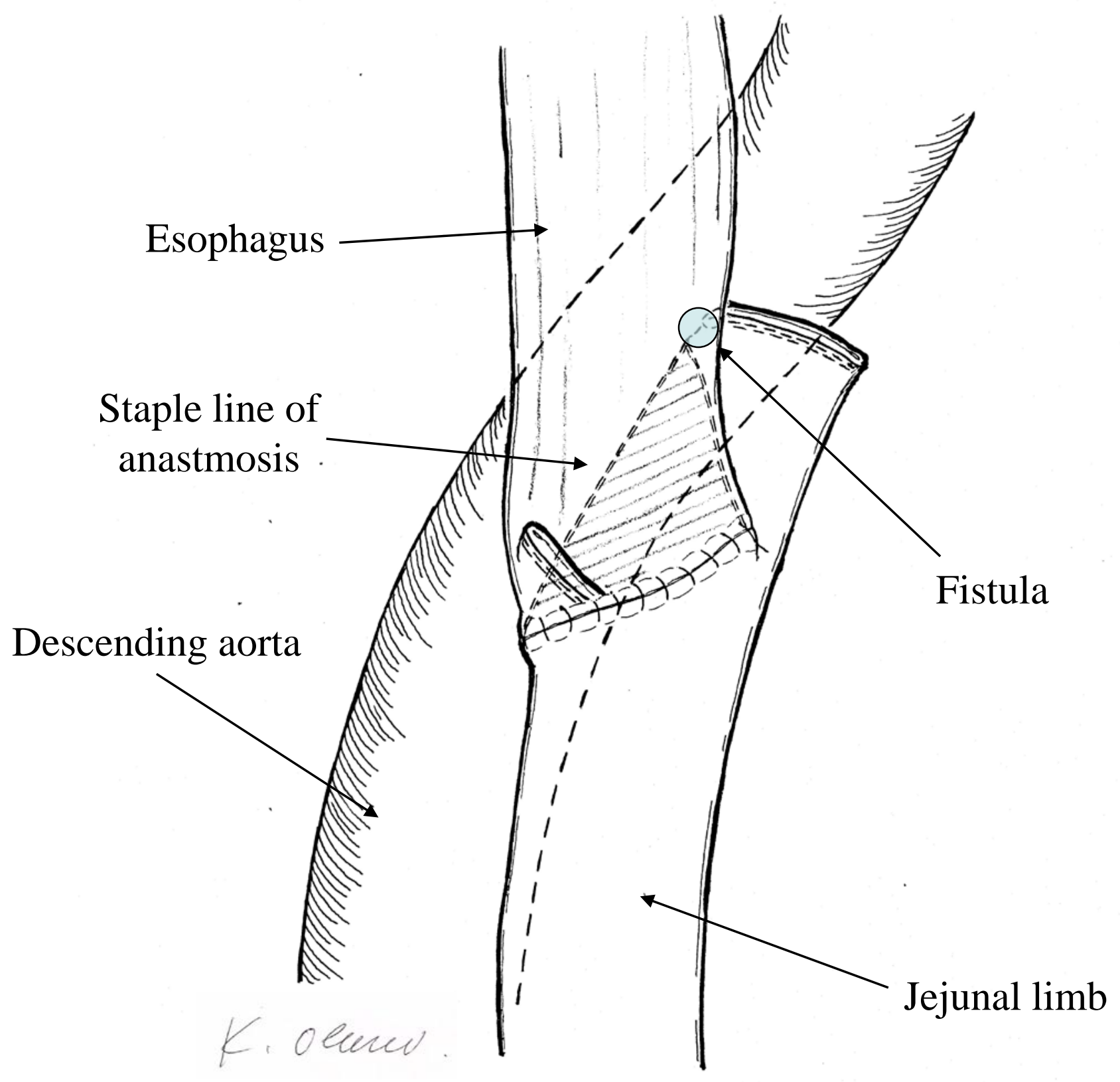

Fig.4 